\title{
Critical current characteristic of various 2G HTS multi-stacked tapes depending on the low external magnetic field
}

\author{
J. Kim, W.S. Lee, H. Jin, and T.K. Ko* \\ School of Electrical \& Electronic Engineering, Yonsei University, \\ 262 Seongsanno, Seodamun-Gu, Seoul 120-749, Republic of Korea
}

(Received 5 February 2014; revised or reviewed 19 March 2014; accepted 20 March 2014)

\begin{abstract}
2 G HTS tapes are widely used for various electric machines. In addition, stacked or parallel connected HTS tapes are essentially used to raise transport current level for large capacity electric machines. Therefore, critical current characteristic of stacked tapes need to be studied. Recently developed 2G HTS tapes are fabricated with various defects doping so that tapes possess pinning center to improve the critical current characteristic. During this process, the critical current is determined minimum value in not perpendicular magnetic field but a specific magnetic field angle according to the reported research. However, the effects of magnetic field angle to critical current of multi-stacked 2G HTS tapes have not been examined. In this paper, field coil which is a race-track coil wound by using an HTS tape with iron-core was fabricated to apply angle adjustable magnetic field to the $2 \mathrm{G}$ HTS tape samples. We measured critical current of single and multi-stacked two tapes that have different characteristic depending on various magnetic field angle and magnitude in liquid nitrogen environment. Furthermore, results of single and multi-stacked tapes were compared and analyzed.
\end{abstract}

Keywords: critical current, stacked 2 G HTS tape, various magnetic field angle

\section{1. 서 론}

2세대 고온 초전도 선재는 높은 임계전류와 임계자장으로 초전도한류기, 발전기, 전동기 및 케이블 등의 전력기기 응용에 널리 쓰인다. 최근 전력기기의 용량이 증가함에 따라, 전력기기에 응용되는 초전도 선재의 통전전류의 레벨을 높이기 위한 방법으로 선재의 병렬연결 및 선재를 적층하는 방법이 연구되고 있다.

초전도체의 임계전류는 vortex-pinning에 의한 영향을 많이 받으며 [1] 특히, 높은 임계전류 값을 갖는 2세대 고온 초전도 선재는 1 세대 고온 초전도 선재와는 다르게 제조과정에서 불순물 도핑을 통하여 pinning center를 인위적으로 만든다. 또한 강력한 pinning force는 vortex들의 움직임을 막아 임계전류를 높인다 [2]. 이러한 과정에서 1 세대 선재와는 달리 도핑물질, 제조방식, 비율조합 등에 따라 수직자장에 의한 영향뿐만 아니라 특정 각도의 입사자장에 대해서 임계전류가 다른 각도에 비해 낮아지는 성질을 가지는 것으로 알려져 있다 [3-5]. 입사자장각도에 따른 임계전류의 변화는 고온 초전도 선재를 사용한 전력기기를 설계할 때 반드시 고려해야 할 사항이다. 1 세대 고온초전도 선재의 입사자장각도에 따른 임계전류 특성은 이미 연구된 바 있고 [6-8] 최근 쓰임이 많아진 2세대 고온초전도 선재에 대해서도 활발한 연구가 진행되고 있다. 일반적으로 높은 전류의 통전을 요구하는 초전도 한류기, 초전도 케이블과 같은 전력 응용에서는 무유도 권선 방법 등 구조상 선재에 가해지는 자장의 크기를 최소화 하는 설계를 가진다. 하지만 적층 선재에서는 통전 전류가 큰 만큼 낮은 자장에 의한 영향이라도 선재의 임계전류 감소에 의한 영향을 파악하는

* Corresponding author: tkko@yonsei.ac.kr
것이 중요하다.

따라서 본 논문에서는 서로 다른 종류의 적층 된 2 세대 선재에 낮은 세기의 자장입사 각도 및 크기에 변화를 주어 그에 따른 임계전류의 변화를 연구하였다. 실험을 위해 HTS선재로 race-track형 코일을 권선하고 철심을 추가한 모듈을 제작하였다. 선재 샘플은 $\mathrm{A}$ 社의 $\mathrm{GdBCO}$ 선재와 $\mathrm{B}$ 社의 $\mathrm{YBCO}$ 선재를 사용하였다. 입사자장의 세기 및 각도에 따라 단일 선재 샘플과 적층 선재 샘플의 임계전류를 측정하였고 실험은 $77 \mathrm{~K}$ 액체질소 환경에서 수행되었으며, 임계전류는 $1 \mu \mathrm{V} / \mathrm{cm}$ 의 기준을 적용해 측정하였다. 두 종류의 선재에 대하여 단일선재, 2 적층 선재 3 적층 선재의 입사자장 각도에 따른 임계전류 특성을 비교하여 분석하였다.

\section{2. 실험장치의 제작 및 실험 방법}

\section{1. 단일 선재 및 적층 선재 샘플제작}

본 실험에서는 $\mathrm{A}$ 社의 copper stabilizer $\mathrm{GdBCO}$ 선재와 $\mathrm{B}$ 社의 stainless steel stabilizer $\mathrm{YBCO}$ 선재를 이용하여 단일 및 적층 샘플을 제작하였다. 선재의 너비는 $\mathrm{GdBCO}$ 선재와 $\mathrm{YBCO}$ 선재가 각각 $4 \mathrm{~mm}, 4.3 \mathrm{~mm}$ 이며 두께는 $0.5 \mathrm{~mm}, 0.15 \mathrm{~mm}$ 이다. 각 선재의 세부사양은 Table I 과 Table II 에 나타내었다. 실험에 사용된 샘플의 길이는 $18 \mathrm{~cm}$ 로 동일하게 제작되었으며 voltage tap은 $8 \mathrm{~cm}$ 간격으로 내었고 선재의 임계전류 기준은 $1 \mu \mathrm{V} / \mathrm{cm}$ 를 적용하였다. 각 선재의 적층 시에는 $\mathrm{In}_{52} \mathrm{Sn}_{48}$ (Melting point $118{ }^{\circ} \mathrm{C}$ )를 사용하였고, 선재를 전류리드에 접합 시에는 구리 바와 샘플의 접합이 적층에 영향을 주지 않도록 하기 위하여 녹는 온도가 더 낮은 $\mathrm{In}_{66.3} \mathrm{Bi}_{33.7}$ (Melting point $72{ }^{\circ} \mathrm{C}$ ) 를 사용하였다. 
TABLE I

SPECIFICATIONS OF THE GDBCO TAPE.

\begin{tabular}{cc}
\hline Parameter & Specifications \\
\hline Average width & $4 \mathrm{~mm}$ \\
Average thickness & $0.1 \mathrm{~mm}$ \\
Stabilizer material & Copper \\
Substrate material & Hastelloy C276 \\
Critical current & 193 A @ 77 K, self-field \\
\hline
\end{tabular}

TABLE II

SPECIFICATIONS OF THE YBCO TAPE.

\begin{tabular}{cc}
\hline Parameter & Specifications \\
\hline Average width & $4.3 \mathrm{~mm}$ \\
Average thickness & $0.15 \mathrm{~mm}$ \\
Stabilizer material & Stainless steel strip \\
Substrate material & Ni-5at\%W \\
Critical current & 96 A @ $77 \mathrm{~K}$, self-field \\
\hline
\end{tabular}

TABLE III

SPECIFICATIONS OF A FABRICATED RACE-TRACK COIL.

\begin{tabular}{cc}
\hline Parameter & Specifications \\
\hline Wire length & $30 \mathrm{~m}$ \\
Length of straight line & $150 \mathrm{~mm}$ \\
Radius of curve & $25 \mathrm{~mm}$ \\
Turns & 53 \\
Inductance & $0.003 \mathrm{mH}$ \\
\hline
\end{tabular}

\section{2. 외부자장 인가 모듈 제작 및 실험 방법}

선재 샘플에 각도에 따른 외부자장을 인가시키기 위해 $\mathrm{B}$ 社의 $\mathrm{YBCO}$ 선재를 이용하여 race-track 형태의 HTS field coil을 권선 하였고, 샘플에 인가되는 자장의 크기를 증가시키고 샘플 면적 방향으로의 균일도를 향상시키기 위해 아래 위로 철심을 추가하였다. 코일의 세부 사양은 Table III에, 모듈의 전체적인 구성도는 Fig. 1에 나타내었다.

자장을 발생시키기 위해 HTS field coil에 $60 \mathrm{~A}, 80 \mathrm{~A}$, $100 \mathrm{~A}, 120 \mathrm{~A}$ 를 통전시켰으며, $60 \mathrm{~A}$ 의 전류를 통전 시켰을 때의 자장 값은 $0.06 \mathrm{~T}$ 이고 $120 \mathrm{~A}$ 의 전류를 통전 시켰을 때의 자장 값은 $0.1 \mathrm{~T}$ 이다. 통전전류에 따라서 발생하는 중심자장 값의 그래프는 Fig. 2에 나타내었다.

단일 및 적층 선재의 입사자장각도에 따른 임계 전류를 측정하기 위하여 모듈 중앙에 샘플을 위치 시키고, 샘플 정 중앙에는 Hall sensor를 부착시켜 자장의 값을 측정하였다. 액체 질소 환경에서 입사자장의 각도를 $0^{\circ}$ (넓은 면에 수직)부터 $90^{\circ}$ (넓은 면에 수평)까지 15 안격으로 조절하며 임계전류를 측정 하였다.

\section{3. 실험결과 및 분석}

\section{1. 단일 및 적층 $\mathrm{GdBCO}$ 선재의 임계전류}

$\mathrm{GdBCO}$ 선재의 단일선재, 2 적층 선재, 3 적층 선재샘플의 입사자장 각도에 따른 임계전류 $I_{c}$ 를 자장을 인가하지 않았을 때의 임계전류 $\mathrm{I}_{0}$ 로 표준화시켜 Fig. 3 의 그래프에 나타내었다. 인가자장이 없을 때 단일 $\mathrm{GdBCO}$ 선재의 임계전류는 $193 \mathrm{~A}$ 로 측정되었다. 인가자장의 크기가 커질수록 임계전류가 감소하였고, 선재의 넓은 방향에

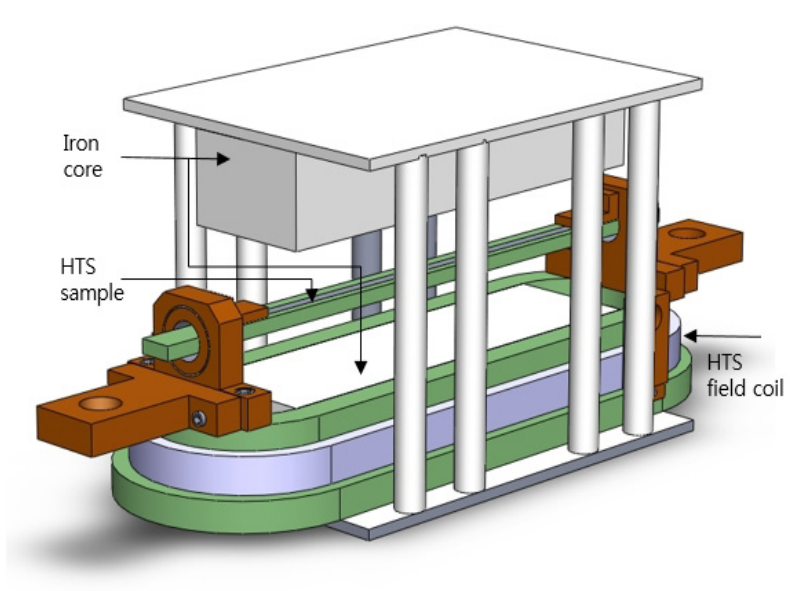

Fig. 1. A schematic of sample test module with an adjustable angle of injected magnetic field.

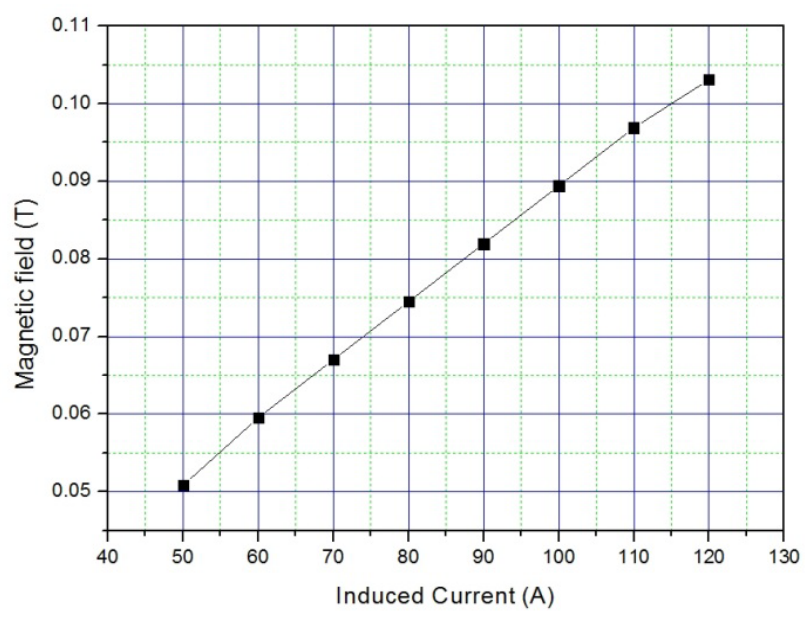

Fig. 2. Magnetic field according to induced current.

수직자장 $\left(0^{\circ}\right)$ 을 인가하였을 때의 임계전류가 최솟값을 나타내므로 $\mathrm{GdBCO}$ 선재는 수직자장에 영향을 많이 받는 것을 알 수 있다. 또한 선재에 인가되는 자장의 각도가 선재의 넓은 방향의 수평자장 $\left(90^{\circ}\right)$ 에 가까이 갈수록 임계전류 감소율이 줄어들어, 입사자장 각도가 커질수록 선재에 미치는 자장의 영향이 줄어드는 것을 알 수 있다.

2적층 선재의 인가자장이 없을 때의 임계전류는 365 A로 단일 선재의 임계전류를 단순히 2 배 한 값의 $95 \%$ 이다. 2 적층 선재의 실험결과는 단일선재의 결과와 유사하게 인가자장의 크기가 커질수록 임계전류가 감소하였고, 수직자장에 영향을 많이 받는 것을 알 수 있다. 또한 입사자장 각도가 커질수록 선재에 미치는 자장의 영향이 줄어드는 것을 볼 수 있다.

3 적층 선재의 인가자장이 없을 때의 임계전류는 480 A이며 단일 선재의 임계전류를 단순히 3 배 한 값의 $82 \%$ 이다. 3 적층 선재의 실험결과 또한 단일선재 및 2 적층 선재의 실험결과와 유사하게 임계전류에 대한 수직자장의 영향이 큰 것을 알 수 있다. Fig 3.(a),(b)와 다르게 (c)에서는 각도의 변화에 따른 그래프의 굴곡이 상대적 으로 심한 형태를 보인다. 이것은 적층 선재의 복잡한 quench 메커니즘 때문인 것으로 보인다. 


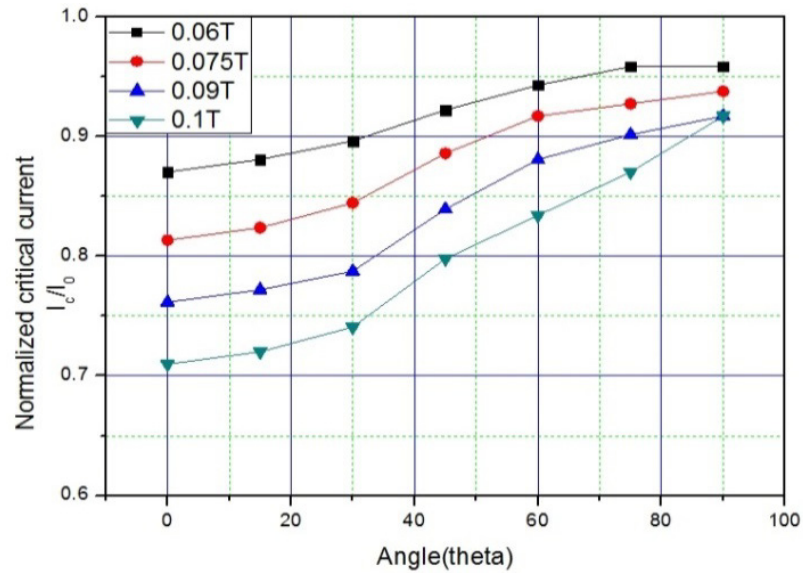

(a)

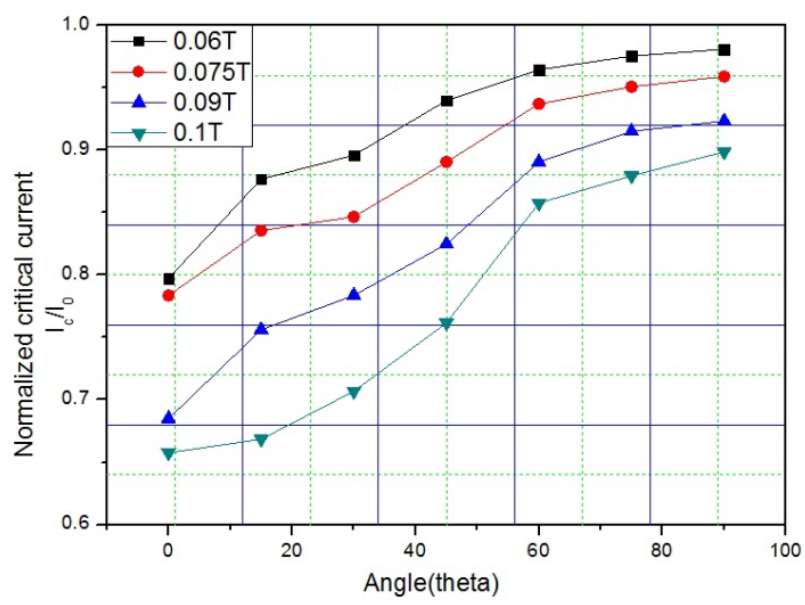

(b)

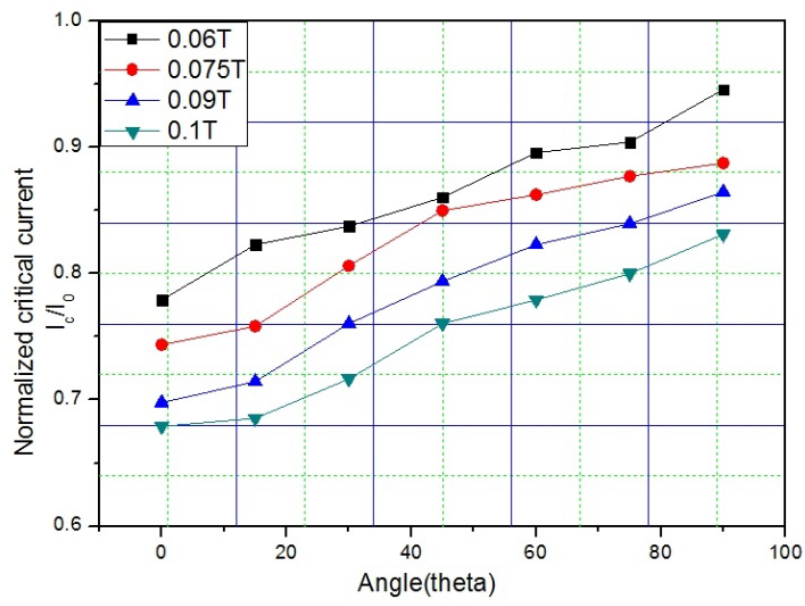

(c)

Fig. 3. Angular dependence of critical current of (a) single, (b) 2-stacked and (c) 3-stacked GdBCO sample.

적층 선재는 특정 한 선재의 quench가 먼저 일어나서 전체에 영향을 끼치기 때문에 단일선재일 때보다 임계전류가 감소 하는 경향을 보인다 [9]. $\mathrm{GdBCO}$ 단일선재 및 적층 선재 에 $0.1 \mathrm{~T}$ 의 입사 자장이 인가될 때 각도에 따른 임계전류 감소율을 Fig. 5 에 나타냈으며 감소율은 다음 식 (1)로 계산 되었다.

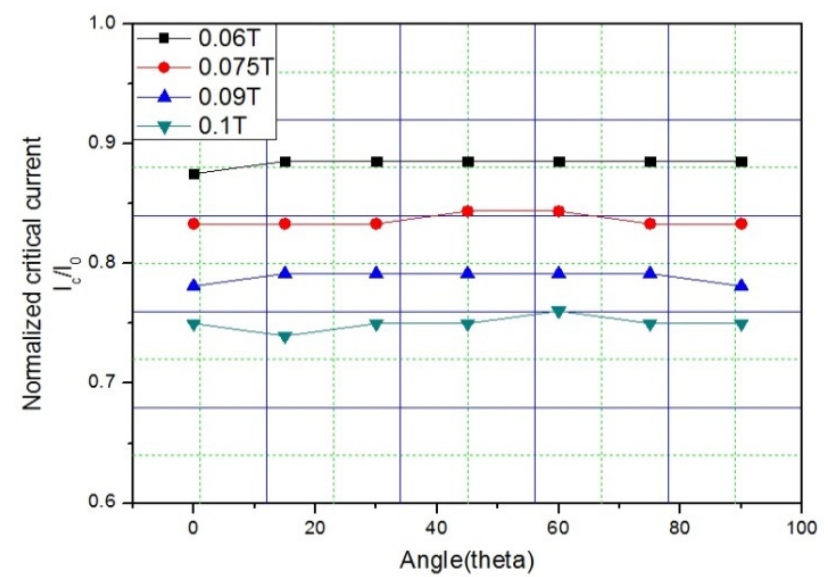

(a)

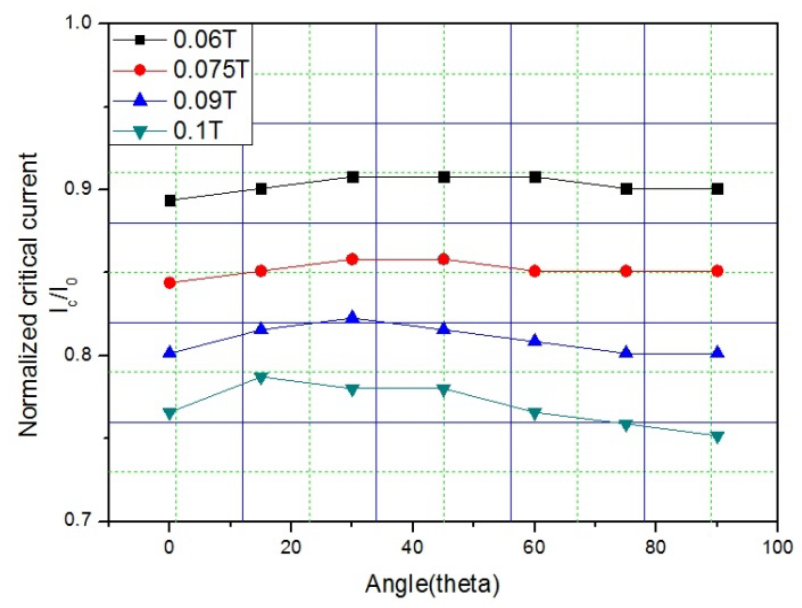

(b)

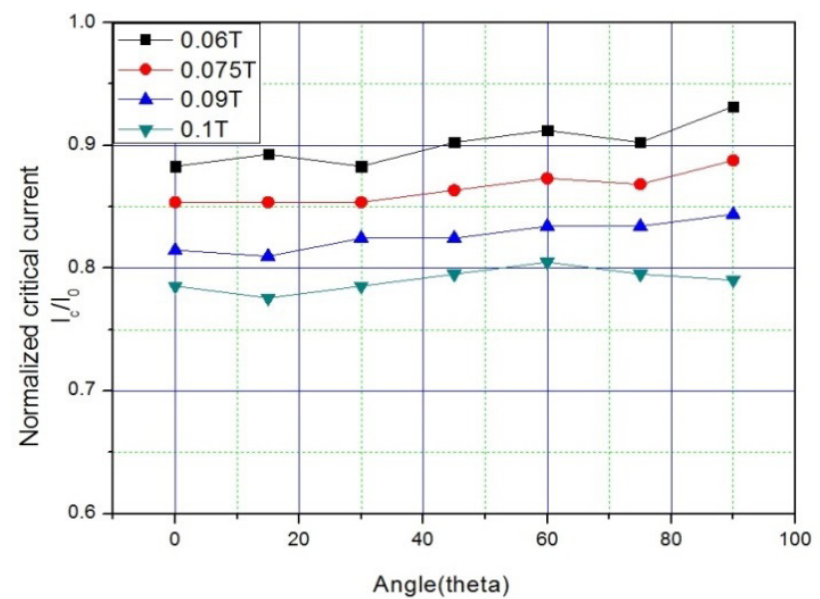

(c)

Fig. 4. Angular dependence of critical current of (a) single, (b) 2-stacked and (c) 3-stacked YBCO sample.

$$
\mathrm{R}=\frac{I_{c}-I_{m}}{I_{c}} \times 100[\%]
$$

위 식에서 $I_{c}$ 는 자장이 인가되지 않았을 때의 임계전류이며, $I_{m}$ 은 입사자장의 크기 및 각도에 따라 측정된 임계전류 값을 의미한다. $0^{\circ}-45^{\circ}$ 일때는 2 적층 


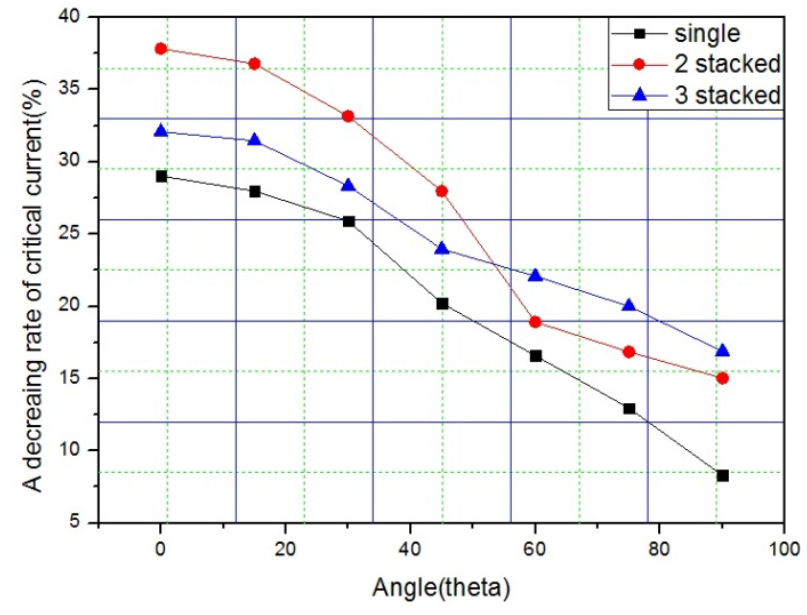

Fig. 5. A decreasing rate of angular dependence of critical current of GdBCO samples in 0.1 T magnetic field.

선재, 3 적층 선재, 단일선재 순으로 각각 $5 \%, 3 \%$ 의 차이를 가지고 감소하고, $60^{\circ}-90^{\circ}$ 일 때는 일 때는 3 적층 선재, 2 적층 선재, 단일선재 순으로 각각 $4 \%, 2 \%$ 의 차이를 가지고 감소한다. $60^{\circ}$ 를 기준으로 2 적층 선재와 3 적층 선재의 실험결과가 역전되는 이유는 선재에 인가되는 자장의 각도가 수평방향 에 가까울수록 적층으로 인해 자장을 차폐할 수 있는 단면적이 줄어들어 나타나는 결과로 예상되며, $\mathrm{GdBCO}$ 선재는 단일선재에 비해 적층 선재가 인가자장에 영향을 더 받는 것을 알 수 있다. 결론적으로, $0.1 \mathrm{~T}$ 수준의 저 자장환경에서는 선재를 적층 하여도 입사 자장각도에 따른 임계전류 감소가 단일 선재일 때와 비슷한 경향을 가지며 감소하므로, 임계전류에 영향을 미치는 특정 입사자장 각도를 단일선재의 실험결과를 통해서 유추할 수 있다.

\section{2. 단일 및 적층 $\mathrm{YBCO}$ 선재의 임계전류}

$\mathrm{YBCO}$ 선재의 단일선재, 2 적층 선재, 3 적층 선재샘플의 입사자장 각도에 따른 임계전류 $\mathrm{I}_{\mathrm{c}}$ 를 자장을 인가하지 않았을 때의 임계전류 $\mathrm{I}_{0}$ 로 표준화시켜 Fig. 4 의 그래프에 나타내었다. 자장을 인가시키지 않았을 때의 단일 $\mathrm{YBCO}$ 선재 임계전류는 $96 \mathrm{~A}$ 로 측정되었다. 인가자장의 크기가 증가함에 따라 임계전류의 약 $5 \%$ 의 값이 지속적으로 균일하게 감소 하는 것을 볼 수 있고, $\mathrm{GdBCO}$ 선재와는 달리 선재에 인가되는 자장의 각도가 $90^{\circ}$ (수평)일 때뿐만 아니라 $0^{\circ}$ (수직)일 때도 임계전류가 감소하지 않았다. $\mathrm{YBCO}$ 선재는 $\mathrm{GdBCO}$ 선재에 비해서 입사자장의 각도가 임계전류에 미치는 영향이 작은 것을 알 수 있다.

2적층 선재의 입사자장이 없을 때의 임계전류는 $141 \mathrm{~A}$ 로 단일 선재의 임계전류를 단순히 2 배 한 값의 $73 \%$ 의 값이다. 2적층 선재의 실험결과는 단일선재의 결과와 유사하게 인가자장의 크기가 증가함에 따라 임계전류의 3 5\% 값이 지속적으로 감소하였지만, 입사자 장의 각도의 변화에는 임계전류의 감소가 없었다.

3 적층 선재의 입사자장이 없을 때의 임계전류는 $205 \mathrm{~A}$ 로 단일 선재의 임계전류를 단순히 3 배 한 값의 $71 \%$ 의 값이다. 인가자장의 크기가 증가함에 따라 임계전류의 약 $3.5 \%$ 의 값이 지속적으로 균일하게 감소 하는 것을 알 수 있다. 3 적층 선재의 실험결과 또한 단일선재 및 2적층선재의 실험결과와 유사하게 입사자장 각도에 따른

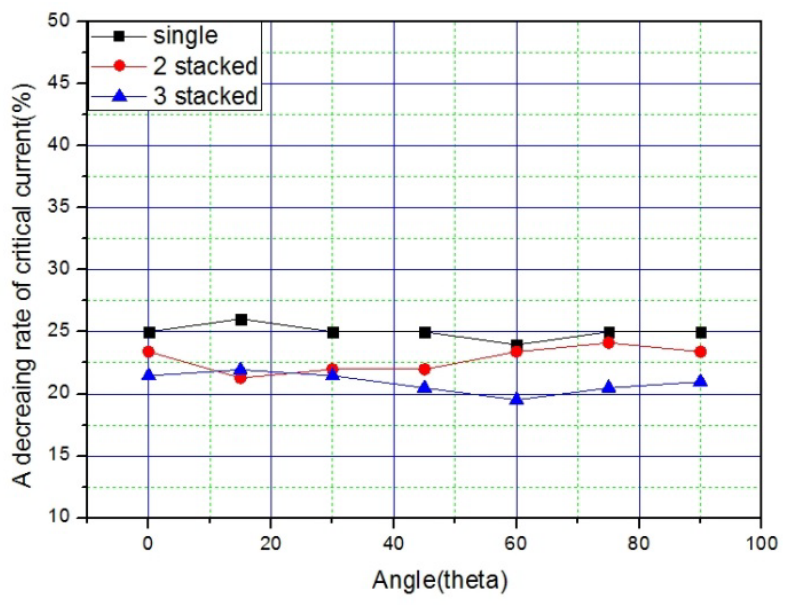

Fig. 6. A decreasing rate of angular dependence of critical current of YBCO samples in $0.1 \mathrm{~T}$ magnetic field.

임계전류 감소가 일어나지 않았다. 균일하지 않은 값은 임계전류의 $5 \%$ 미만의 오차로 예측된다.

Fig. 6은 $\mathrm{YBCO}$ 단일선재 및 적층 선재에 $0.1 \mathrm{~T}$ 의 입사자장이 인가될 때 각도에 따른 임계전류 감소율을 나타냈으며, 감소율은 식 (1)로 계산되었다. 감소율은 대체로 단일 선재, 2적층선재, 3적층선재 순으로 점점 작아지는 것을 볼 수 있다. 이러한 결과는 적층 수가 많아질수록 인접한 초전도 선재가 자계의 영향을 차폐하기 때문인 것으로 예상된다. $\mathrm{YBCO}$ 선재의 substrate층은 자화 특성을 가지는 $\mathrm{NiW}$ 기판이며, 자기포화영역 전의 저 자장이 인가될 때 초전도층으로 인가되는 자장을 막아 전체적으로 봤을 때 초전도 선재에 미치는 자장의 영향이 많지 않을 것으로 예상된다.

$\mathrm{YBCO}$ 선재는 단일선재와 적층 선재 모두 임계전류에 대한 입사자장 각도의 영향이 작은 것을 알 수 있으며, 단일선재와 적층 선재의 임계전류 특성이 비슷하여 $0.1 \mathrm{~T}$ 수준의 저 자장환경에서는 선재 적층 시에도 단일 선재의 결과를 통해서 유추할 수 있을 것이다.

\section{4. 결 론}

전력기기의 용량이 증가함에 따라 통전전류를 높이기 위해 2 세대 고온초전도 선재가 적층 형태로 쓰이며, 적층 된 선재의 입사자장각도에 따른 임계전류 감소율이 전력기기를 설계할 때 중요한 요소가 된다. 따라서 본 논문에서는 입사자장의 각도를 변화시켜 선재에 인가할 수 있는 모듈을 제작하고, 두 종류의 선재를 이용하여 단일 선재 및 다 적층 샘플을 제작하여 입사자장의 크기와 각도에 따른 임계전류 특성을 비교하였다. 실험결과를 바탕으로 다음과 같은 결론을 내릴 수 있다.

1. $\mathrm{A}$ 社의 $\mathrm{GdBCO}$ 선재는 단일 선재 및 적층 선재 모두 입사자장의 크기가 증가할수록 임계전류가 감소하며, 선재의 넓은 방향의 수직방향 인가자장에 영향을 많이 받는다.

2. $\mathrm{B}$ 社의 $\mathrm{YBCO}$ 선재는 단일 선재 및 적층 선재 모두 입사자장의 크기가 증가할 때는 임계전류가 감소하지만, 입사자장 각도의 변화에는 임계전류에 
대한 자장의 영향이 적다. 적층을 할수록 선재가 외부 입사자장을 차폐하여 임계전류 감소율이 작아진다.

$0.1 \mathrm{~T}$ 수준의 저 자장 환경에서는 두 선재 모두 단일 선재와 적층 선재의 입사자장 각도에 따른 임계전류의 감소율은 차이가 있지만 감소경향이 비슷하여, 2 세대 고온초전도 적층 선재의 전력기기 초기설계에는 단일 선재의 결과를 적용할 수 있지만 정확한 설계에는 적층 선재의 입사자장 각도에 따른 임계전류 특성 실험이 필요할 것으로 예상된다.

\section{ACKNOWLEDGMENT}

This research was supported by National R\&D Program through the National Research Foundation of Korea(NRF) funded by the Ministry of Science, ICT \& Future Planning (No. 2012M1A7A1A02034484).

\section{REFERENCES}

[1] K. Matsumoto, T. Horide, K. Osamura, M. Mukaida, Y. Yoshida, A Ichinose and S. Horii, "Enhancement of critical current density of YBCO films by introduction of artificial pinning centers due to the distributed nano-scaled $\mathrm{Y} 2 \mathrm{O} 3$ islands on substrates," Physica $C$. Superconductivity, vol. 412-414, Part 2, pp. 1267-1271, Oct. 2004
[2] S. W. Kim, S. Y. Hahn, Introduction to engineering Superconductivity, Daeyoungsa, 2004, pp.43-45.

[3] T. Matsunamia, Y. Ichinoa, Y. Yoshidaa, A. Ichinoseb and K. Matsumotoc, "Variation of applied field angular dependence of critical current density in YBCO thin films against deposition temperature and composition," Physics Procedia, vol. 27, pp. 236 239, Oct. 2011.

[4] S. Wimbush and N. Long, "The interpretation of the field angle dependence of the critical current in defect-engineered superconductors," New Journal of Physics, vol. 14, pp. 083017-083041, Aug. 2012.

[5] K. Takahashi, H. Kobayashi, Y. Yamada, A. Ibi, H. Fukushima, M. Konishi, S. Miyata, Y. Shiohara, T. Kato and T. Hirayama, "Investigation of thick PLD-GdBCO and $\mathrm{ZrO} 2$ doped GdBCO coated conductors with high critical current on PLD-CeO2 capped IBAD-GZO substrate tapes," Supercond. Sci. Technol. vol. 19, pp. 924-929, Sep. 2006.

[6] S. W. Lee, M. Park, J. Sim, G. Cha and J. K. Lee, "Critical Current Characteristic of HTS Stacked Tapes in External Field," Proceeding of the KIEE Summer Conference, vol. B, pp.903-905, July. 2002.

[7] O. van der Meer, B. ten Haken and H.H.J. ten Kate, "A model to describe the angular dependence of the critical current in a Bi-2223/Ag superconducting tape," Physica C: Superconductivity, vol. 357-360 Part 2, pp. 1174-1177, Aug. 2001.

[8] T Nakamura, S Tsuchiya, A Fujio, T Hoshino, I Muta and M Yamaguchi, "Angular dependence of E?J characteristics and dissipative properties in Bi-2223/Ag tape," Supercond. Sci. Technol, vol. 15, pp. 230-235, Feb. 2002.

[9] S. W. Kim, S. Y. Hahn, Introduction to engineering Superconductivity, Daeyoungsa, 2004, pp. 72-73. 